\title{
Comparison of Human Exploration Architecture and Campaign Approaches
}

\author{
Kandyce Goodliff ${ }^{1}$ and William Cirillo ${ }^{2}$ \\ NASA Langley Research Center, Hampton, VA, 23681 \\ Bryan Mattfeld ${ }^{3}$ and Chel Stromgren ${ }^{4}$ \\ Binera, Inc., Silver Spring, MD, 20910 \\ and \\ Hilary Shyface ${ }^{5}$ \\ Analytical Mechanics Associates, Inc., Hampton, VA, 23666
}

As part of an overall focus on space exploration, National Aeronautics and Space Administration (NASA) continues to evaluate potential approaches for sending humans beyond low Earth orbit (LEO). In addition, various external organizations are studying options for beyond LEO exploration. Recent studies include NASA's Evolvable Mars Campaign and Design Reference Architecture (DRA) 5.0, JPL's Minimal Mars Architecture; the Inspiration Mars mission; the Mars One campaign; and the Global Exploration Roadmap (GER).

Each of these potential exploration constructs applies unique methods, architectures, and philosophies for human exploration. It is beneficial to compare potential approaches in order to better understand the range of options available for exploration. Since most of these studies were conducted independently, the approaches, ground rules, and assumptions used to conduct the analysis differ. In addition, the outputs and metrics presented for each construct differ substantially.

This paper will describe the results of an effort to compare and contrast the results of these different studies under a common set of metrics. The paper will first present a summary of each of the proposed constructs, including a description of the overall approach and philosophy for exploration. Utilizing a common set of metrics for comparison, the paper will present the results of an evaluation of the potential benefits, critical challenges, and uncertainties associated with each construct. The analysis framework will include a detailed evaluation of key characteristics of each construct. These will include but are not limited to: a description of the technology and capability developments required to enable the construct and the uncertainties associated with these developments; an analysis of significant operational and programmatic risks associated with that construct; and an evaluation of the extent to which exploration is enabled by the construct, including the destinations visited and the exploration capabilities provided at those destinations. Based upon the comparison of constructs, the paper will identify trends and lessons learned across all of the candidate studies.

\footnotetext{
${ }^{1}$ Aerospace Engineer, Space Missions Analysis Branch, MS 462, AIAA Senior Member.

${ }^{2}$ Senior Researcher, Space Missions Analysis Branch, MS 462, non-AIAA Member.

${ }^{3}$ Junior Analyst, 8455 Colesville Road Suite 1075, AIAA Member.

${ }^{4}$ Vice President/Chief Scientist, 8455 Colesville Road Suite 1075, AIAA Member.

${ }^{5}$ Project Engineer, 21 Enterprise Parkway, Suite 300, AIAA Member.
} 


\section{Nomenclature}

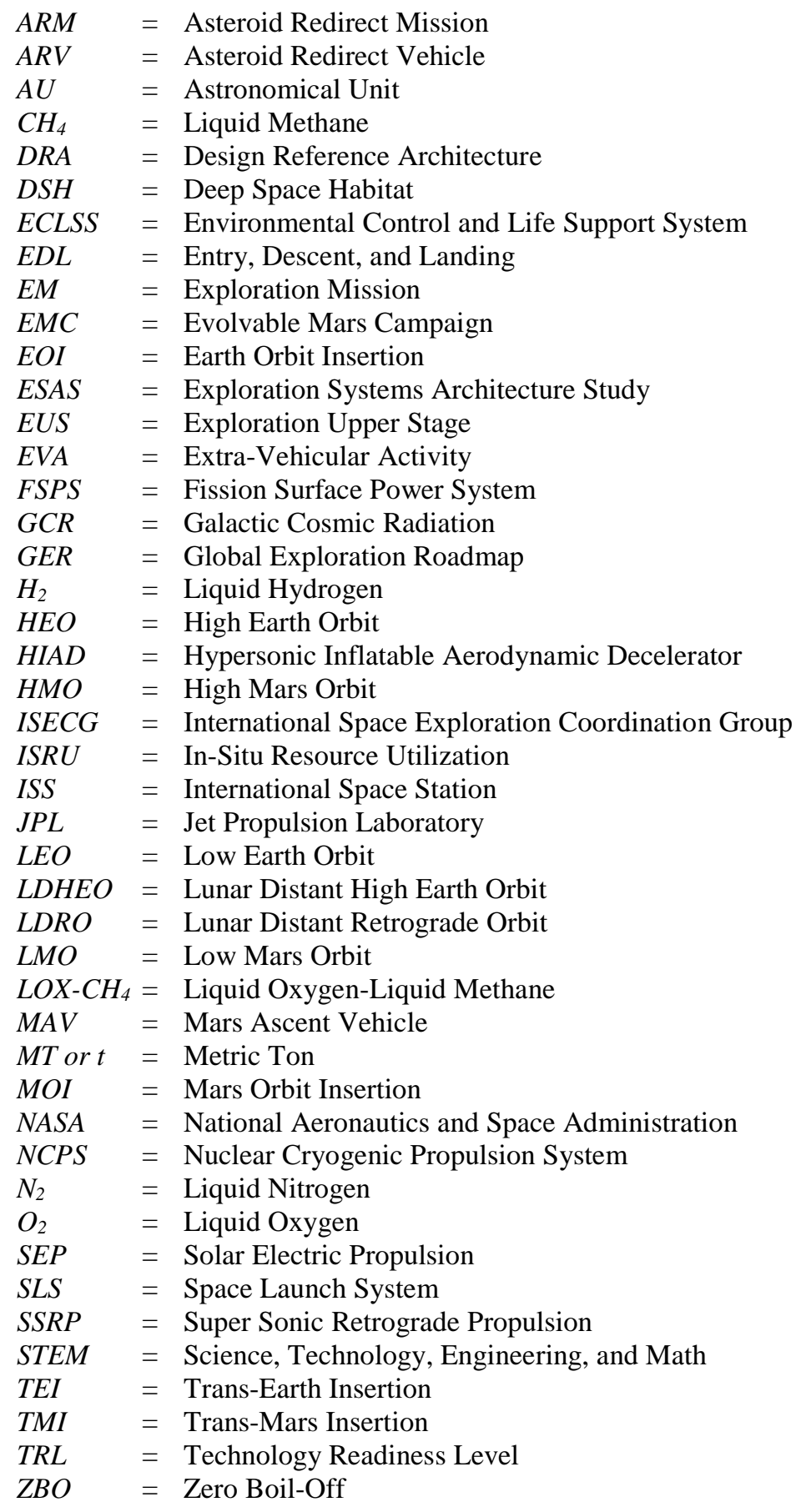

\section{Introduction}

S humans aspire to explore beyond low Earth orbit, Mars is a primary point of focus. Over the past several Ayears, there have been numerous studies that have identified different ways to enable human exploration of Mars. The National Aeronautics and Space Administration (NASA), other international space agencies, and commercial ventures are all exploring methods to send humans to Mars, either to the surface or to the vicinity of Mars and its moons. Some of these efforts have a goal of merely getting to and exploring Mars, while others aim for permanent settlement. Several studies describing potential exploration architectures have been published over the past few years. NASA released Mars Design Reference Architecture (DRA) 5.0 along with an Addendum in 2009. 
A second Addendum followed in 2014. Currently, NASA is investigating the Evolvable Mars Campaign (EMC), which outlines a long-term exploration strategy. In addition, NASA is working with its international partners in the formulation and updating of the Global Exploration Roadmap (GER). NASA's Jet Propulsion Laboratory (JPL) has developed an approach to sending humans to Mars called the 'JPL Minimal Mars Architecture'. Also, several private venues have explored mission concepts and campaigns to explore Mars, including the Inspiration Mars Foundation and the Mars One Foundation. While all of these studies vary greatly in approach and objectives, they all have one goal in common: sending humans to Mars.

Section 2 of this paper will introduce each of the studies listed above with a technical overview and description of the underlying philosophy. A comparison of the architectures and campaigns is presented in Section 3 including performance, sustainability, and the potential risk impacts and challenges of each study. Lessons learned from each study are addressed in Section 4 and conclusions are presented in Section 5.

\section{Overview of Architecture and Campaign Approaches}

As part of an overall focus on space exploration, NASA continues to evaluate potential approaches for sending humans beyond low Earth orbit (LEO). In addition, various external organizations are studying alternative approaches for beyond LEO exploration. The recent studies include NASA's EMC and DRA 5.0; JPL's Minimal Mars Architecture; the Inspiration Mars mission; the Mars One campaign; and the Global Exploration Roadmap (GER).

\section{A. NASA's Evolvable Mars Campaign $[1,2,3,4]$}

NASA's EMC evaluates potential long-term strategies for extended human exploration of Mars in support of the policies outlined in the 2010 NASA Authorization Act and U.S. National Space Policy [1]. These strategies do not necessarily reflect "the plan" for sending humans to Mars, but rather explores several pathways to achieving NASA's goals by evaluating potential architectures and campaign options. These assessments lead to an understanding of the common capabilities required across potential pathways and inform key decisions regarding capability development. The EMC is driven by the following strategic principles for sustainable exploration [2]:

- Implementable in the near-term with the buying power of current budgets and in the longer term with budgets commensurate with economic growth;

- Exploration enables science and science enables exploration;

- Application of high Technology Readiness Level (TRL) technologies for near term missions, while focusing sustained investments on technologies and capabilities to address challenges of future missions;

- Near-term mission opportunities with a defined cadence of compelling and integrated human and robotic missions providing for an incremental buildup of capabilities for more complex missions over time;

- Opportunities for U.S. commercial business to further enhance the experience and business base;

- Multi-use, evolvable space infrastructure, minimizing unique major developments;

- Substantial international and commercial participation, leveraging current International Space Station (ISS) and other partnerships.

The EMC applies a phased approach to exploration. The first phase, 'Earth Reliant', focuses on ISS as an effective platform for gaining knowledge that enables beyond LEO exploration (e.g. human research for long duration). The second phase, 'Proving Ground', focuses on utilizing cis-lunar space to test and demonstrate capabilities and technologies needed for the third phase, 'Earth Independent.' Proving Ground activities include validation of: the Space Launch System (SLS) and the Orion crew vehicle; the Asteroid Redirect Mission (ARM), including the Asteroid Redirect Vehicle (ARV) and Solar Electric Propulsion (SEP); and the initial deep space habitation. In the third phase, the focus is on development of the Mars transportation, entry, descent, and landing (EDL), and surface capabilities, and ultimately sending humans to the Martian surface. Figure 1 captures one potential pathway from the EMC, displaying the capabilities and missions leading up to the eventual placement of humans on Mars. 


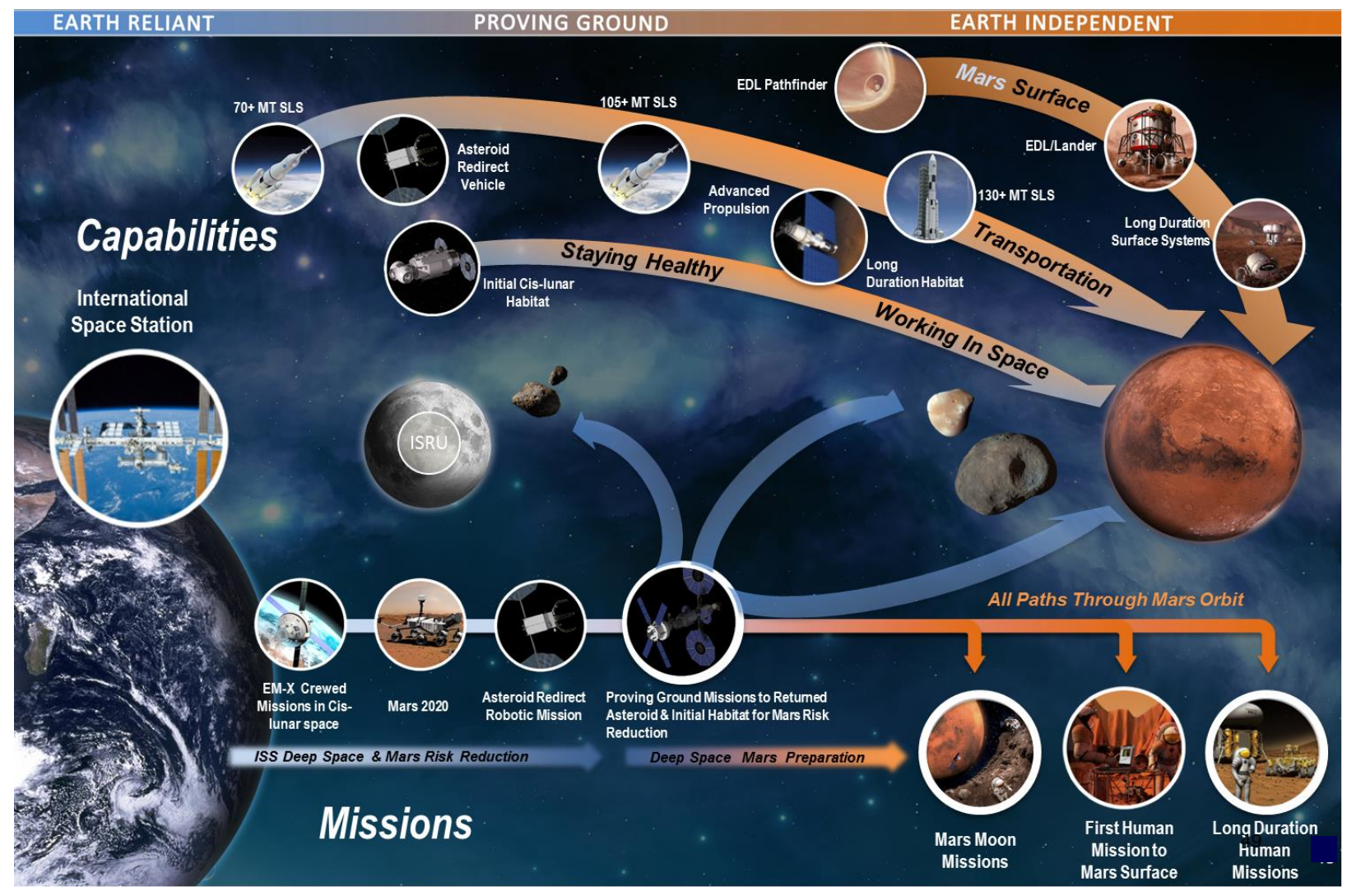

Figure 1. Evolvable Mars Campaign [1]

This example pathway was constructed as a point of reference for analysis and comparison. The point of reference was formulated to address and capture the key strategic principles, while also bounding the scope of the analysis within the ground rules, assumptions, and constraints, with the realization that future technical and programmatic assessments will inform potential future derivatives.

A 'Mars vicinity and Phobos, followed by mission to Mars surface' concept was selected for initial study and served as a mechanism to begin identifying capabilities and challenges associated with all destinations and to inform development and assessment of additional options. The point of reference campaign starts with the Earth Reliant phase with testing capabilities and long duration objectives on ISS. Next follows the Proving Ground with a series of Exploration Missions, utilizing the SLS and Orion; emplacement of the initial Cis-lunar habitation for testing and demonstrating capabilities in a deep-space environment; and several robotic missions, including the Asteroid Redirect Robotic mission and robotic missions to Mars. In the 'Earth Independent' phase, the first crew mission to the Mars vicinity would visit a pre-deployed habitat on a moon of Mars. The crew of four would stay for the majority of the Mars vicinity duration on the Martian moon, completing science and exploration objectives, and then transit back to Earth. The transit habitat would be captured into a lunar vicinity orbit for restocking and reuse for subsequent transits to Mars. The second (and each successive) crew mission would then be to the Mars surface. For each of these missions, the majority of the duration in Mars vicinity would be spent on the surface (i.e. 300-500 day surface missions). These missions would be supported with pre-deployed cargo landers to Mars surface and orbit. The landers are assumed to either utilize aerocapture at Mars with a Hypersonic Inflatable Aerodynamic Decelerator (HIAD) or propulsive capture to land $18 \mathrm{t}$ of cargo on the surface. The Mars Ascent Vehicle (MAV) is assumed to have an integrated In-situ Resource Utilization (ISRU) plant to produce oxygen from the atmosphere. Both ascent and descent stages utilize liquid oxygen liquid methane $\left(\mathrm{LOX}-\mathrm{CH}_{4}\right)$ engines with zero boil off $(\mathrm{ZBO})$ propellant storage. This reduces the need to send oxygen from the Earth and requires only that methane be sent with the MAV. Other surface systems would likely include long duration habitation, pressurized rovers, fission surface power system (FSPS), and surface extra-vehicular activity (EVA) suits. In the EMC, surface infrastructure at a single location would be revisited and reused by each subsequent crew, building capabilities over time.

As part of the EMC, two different options are being explored for in-space propulsion. These options differ in how both pre-deployed cargo missions and crewed missions are delivered to Mars. The first option - 'EMC-Split' 
[3] - utilizes unique propulsion concepts for pre-positioned Earth return stages, destination systems, and lander flights and for crewed flights. A SEP propulsion system, derived from the ARM SEP system, is utilized to preposition all cargo and landers, utilizing low-energy trajectories. Landers use an aerocapture system at Mars, employing the same aerocapture system that will be used for Mars entry. Crewed flights are delivered entirely by a chemical $\mathrm{LOX}-\mathrm{CH}_{4}$ system without the use of aerocapture at Mars. The second option - 'EMC-Hybrid' [4] utilizes a common propulsion system for both cargo/lander and crew flights. In this case, the hybrid propulsion system is composed of an ARM-derived SEP system and a storable hydrazine chemical system working in conjunction. This system is used for all propulsive events and aerocapture is not utilized for either crew or cargo. The exploration systems for Mars moons and Mars surface are the same for both options, although the elements may be delivered to Mars in different manners.

\section{B. NASA's Mars Design Reference Mission 5.0 [5, 6, 7]}

Mars DRA 5.0 is the reference architecture developed by NASA prior to the EMC effort. DRA 5.0 was developed in 2007-2008 as a response to the NASA Authorization Act of 2005 and recognizing the need to update the Mars design reference architecture based on the outcome of Exploration Systems Architecture Study (ESAS) conducted in 2005. In addition, NASA was developing the Lunar Architecture Team studies in 2006-2007 and determined a further need to identify the follow-on missions to lunar exploration. The follow-on missions, specifically Mars missions, would benefit from the lunar program and associated test campaign, through testing of capabilities and technologies for the Mars missions. [5]

DRA 5.0 is a relatively technologically ambitious approach that seeks to maximize mission performance and objective satisfaction, while minimizing both crew and mission risks. Although DRA 5.0 did not define near- and mid-term campaign steps to reach Mars, it did define a sustained Mars surface exploration campaign. DRA 5.0 "describes the systems and operations that would be used for the first three missions to explore the surface of Mars by humans" [5]. DRA 5.0 implements a "Commuter" surface architecture, "which would have a centrally located, monolithic habitat, two small pressurized rovers, and two unpressurized rovers" [5]. The surface infrastructure also assumes the use of nuclear power for surface operations and ISRU to produce ascent oxidizer. This surface architecture allows the flexibility of long duration stays at diverse sites. Each set of surface elements would be used only by a single crew, with subsequent crews visiting new sites.

DRA 5.0 was developed using the proposed Constellation architecture, including the Ares launch vehicles and Orion crew system. The DRA 5.0 architecture is a split-mission approach, in which two landers, one with the surface hardware and another with crew ascent/descent vehicle, are pre-positioned at Mars. At the next opportunity, a crew of six transfers to Mars and descends to the surface, where they spend up to 500 days on the Martian surface before ascending and returning to Earth. The baseline DRA 5.0 architecture assumes use of a Nuclear Cryogenic Propulsion System (NCPS). This approach is repeated for the first three crew missions. The mission architecture for DRA 5.0 is depicted in Figure 2. 


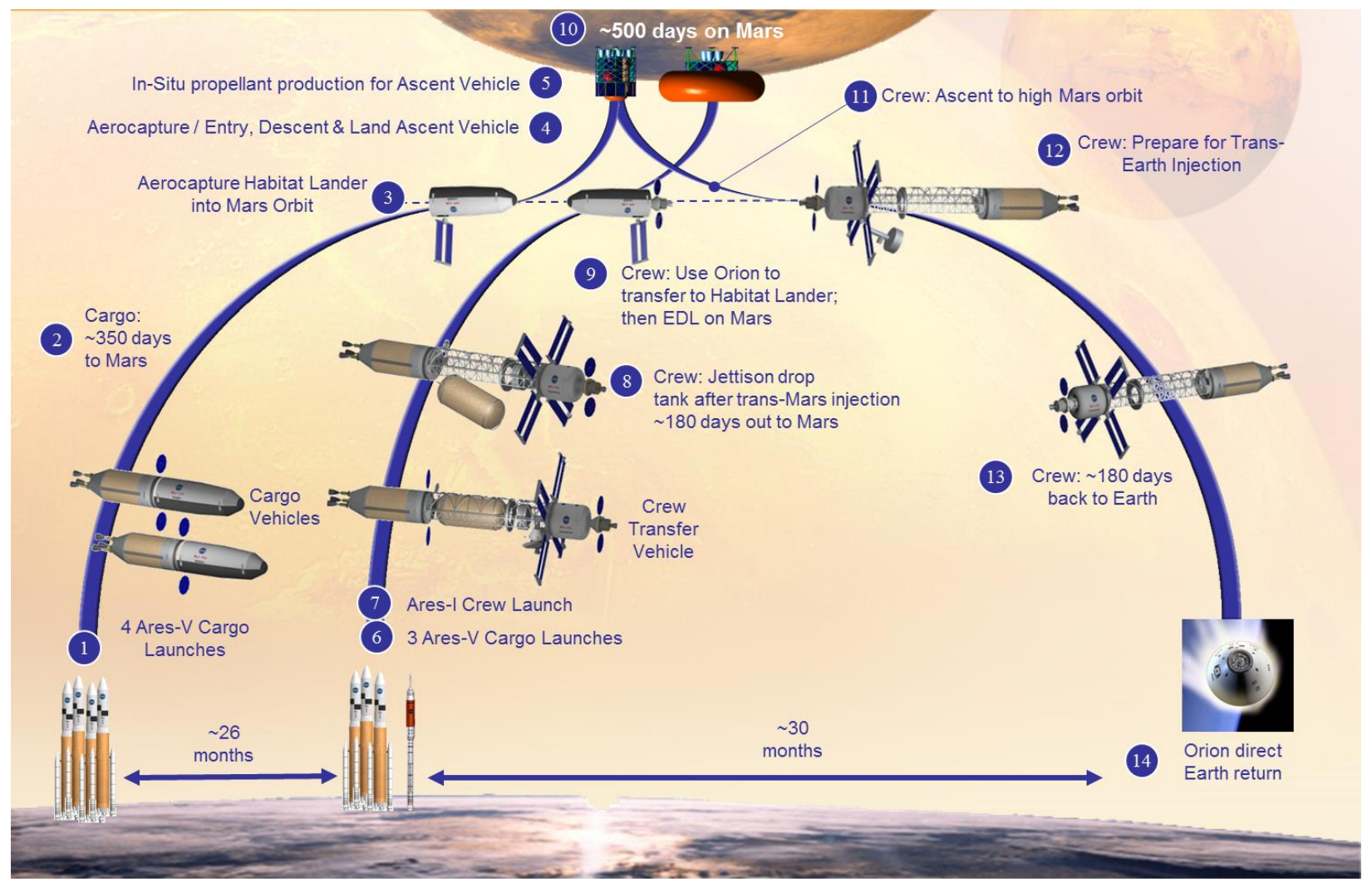

Figure 2. NASA's Mars Design Reference Architecture 5.0 [5]

\section{JPL Minimal Mars Architecture $[8,9,10]$}

The Jet Propulsion Laboratory has developed a human Mars option that is referred to as the 'Minimal' architecture. The basic philosophy behind the development of this option was to minimize the scope of new capability developments that are required to enable the architecture. This includes limiting both the number of new developments and the use of low TRL technologies. The schedule for the Minimal architecture was specifically developed to support affordability, to fit all development and operational costs within the projected NASA exploration budget. [8]

The campaign described for the JPL Minimal approach includes a progressive build-up of capabilities. The initial mission to Mars vicinity is to Phobos for an extended stay. The second mission is a short surface stay mission, during which a crew of two will spend a maximum of 24 days on the Mars surface, with the remaining destination vicinity time spent in Mars orbit. The third mission would be a long-stay surface mission, in which the entire crew would descend to Mars, living in pre-emplaced infrastructure for a period of one year.

The Minimal architecture employs a 'split' delivery approach, pre-positioning cargo at Mars prior to a crewed mission. Cargo missions are pre-deployed utilizing a SEP system. Pre-deployed cargo includes the return propulsion stage to send the crew back to Earth after the stay at Mars. Mars landers (one for the short stay mission and three for the long stay) are pre-positioned in Mars orbit via the SLS Exploration Upper Stage (EUS) and aerocapture at Mars. Finally, the crew is sent to Mars using the EUS and a storable chemical stage. The crew rendezvous with the fully fueled Mars lander and descend to the surface. Both ascent and descent stages utilize storable chemical engines. For the short-stay mission, the crew lives out of the lander cabin, exploring the surface. For the long-stay, they live out of a pre-emplaced habitat. At the end of the surface stay the crew then ascends in a MAV and rendezvous with a separate chemical boost stage, pre-positioned in low Mars orbit (LMO). The boost stage delivers the MAV back to the transit vehicle in high Mars orbit (HMO) for return to Earth. The architecture approach for the short stay Mars surface JPL Minimal mission variant is shown in Figure 3. The long stay mission is similar but incorporates four additional SLS launches to launch the two additional landers and two EUS stages. 


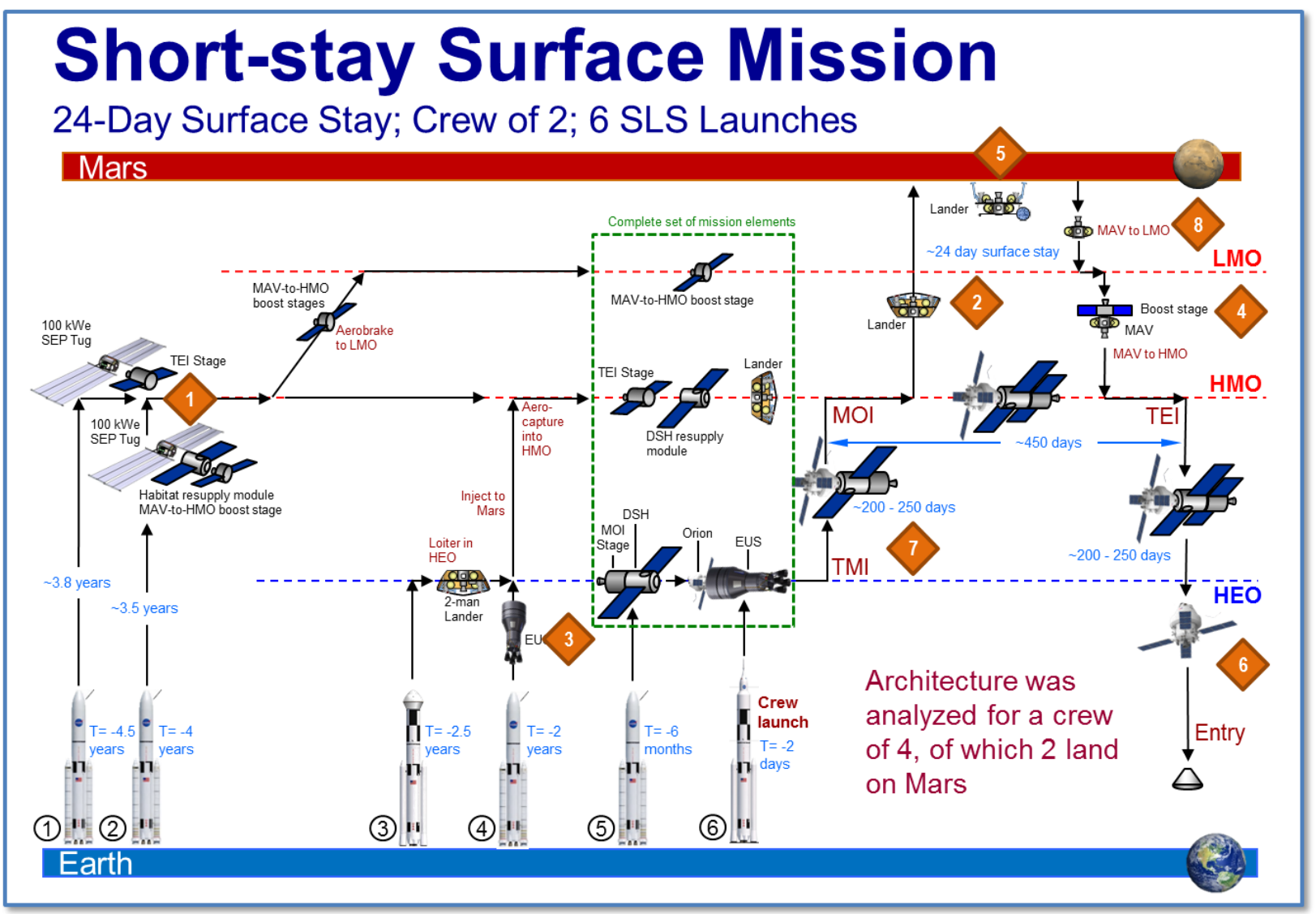

Figure 3. JPL Minimal Mars Architecture [8]

D. Inspiration Mars Mission [11, 12, 13]

In 2013, the Inspiration Mars Foundation, a 501C3 non-profit organization, advocated for a crewed flyby mission of Mars to take place in 2018. The foundation subsequently has changed their proposal to a flyby mission to take place in 2021 [13]. Through participation of its membership, the organization has defined a conceptual level mission description for the 2021 flyby mission. The goals of this mission include: demonstrating the feasibility of human missions to Mars; fostering knowledge, experience and momentum for space exploration; addressing technical risks in human deep space exploration; conducting research on the human physiology of deep space travel; inspiring youth through science, technology, engineering and math (STEM) education and motivation; and enabling in-depth public participation [12].

The Inspiration Mars 2021 mission is a Venus and Mars fly-by mission concept that would take place in 20212022. A two-person crew would launch from Earth on a single SLS in an Orion crew capsule with a deep space habitat. The stack would immediately depart on a free return trajectory, propelled by the EUS, that would take the crew on a flyby of Venus and then on a flyby of Mars. The crew returns to Earth after a total 580-day mission. Figure 4 depicts the transit spacecraft at Mars flyby. The plan largely involves the use of currently available or soon to be available capabilities.

Inspiration Mars is not a holistic approach for conducting human missions to the Martian surface; rather, it is an option for a near-term mission to Mars space, intended to help build capabilities and knowledge. As such, Inspiration Mars would be a part of a broader Mars human exploration campaign. The Inspiration Mars mission has been proposed as an alternative early mission option as part of the EMC. The intention would be for Inspiration Mars to serve as an opportunity to test Mars transit and exploration habitation systems in a relevant mission environment. 


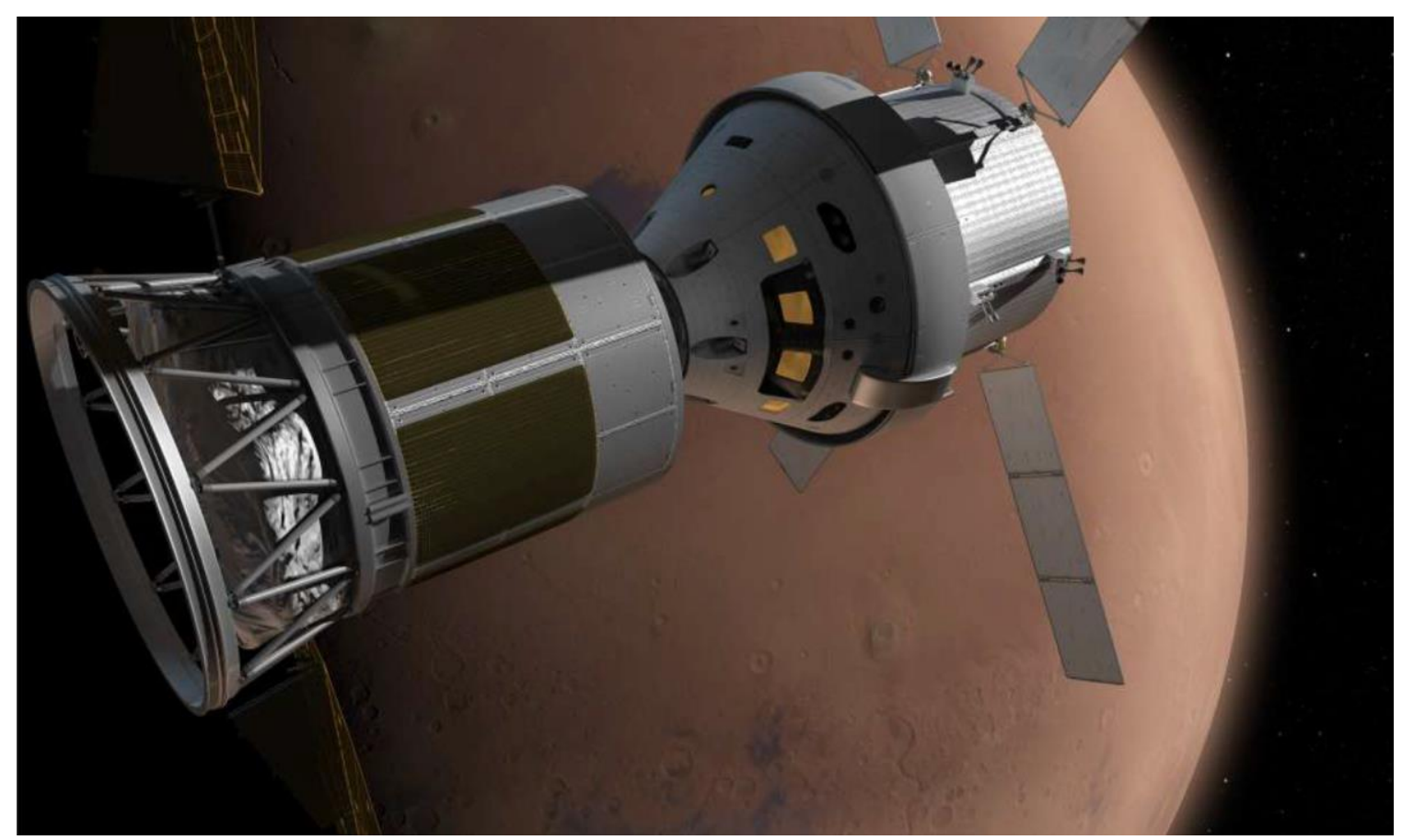

Figure 4. Transit Spacecraft at Mars Flyby (Courtesy Inspiration Mars) [11]

\section{E. Mars One Campaign [14, 15]}

In 2012, the Mars One Corporation, a non-government, private organization, announced its plan to establish a human settlement on Mars, beginning in 2023. As part of the Mars One campaign, a series of one-way missions to the Mars surface are conducted, progressively delivering infrastructure and astronauts. The campaign is built on the philosophy that the absence of Earth return capabilities greatly reduces mission risk, cost, and complexity ultimately providing the most feasible path to putting humans on Mars using existing technology [14]. Sustainability and self-sufficiency of permanent crews is enabled via extensive ISRU on the Martian surface. Continuous infrastructure buildup provides inherent redundancy for surface crews as the campaign progresses.

In each mission, six cargo landers are pre-positioned at Mars, followed by a crewed lander. Initial mobility rovers are launched in 2022 and cargo missions in 2024, with surface infrastructure expected to be fully operational by 2025. The first crew of four departs for Mars in 2026 and arrives in 2027. Subsequent crews of four launch every two years after the initial crew, increasing the size of the settlement and the level of self-sufficiency with each successive mission. There is no capability to return astronauts to Earth as part of this approach.

ISRU is an integral part of the surface campaign. A surface soil extraction/heating system provides potable water and oxygen production capability for crew. Oxygen is produced via electrolysis of extracted water. Mars atmospheric extraction is utilized to produce nitrogen and argon for habitat atmosphere. The majority of crew food will eventually be grown locally on the surface. Surface power is provided from thin film solar arrays that are deployed robotically prior to crew arrival at Mars. No surface mobility is explicitly defined for the crew. Large robotic rovers are assumed to provide asset repositioning, solar array deployment, ISRU support, and general site preparation. The surface habitat is a modular architecture that joins the six cargo landers to create a single connected surface habitat. There are three variants of habitat modules - living units, life support units, and cargo units. Living units include a large inflatable habitation structure, airlock, and crew waste and hygiene support. Life support units provide Environmental Control and Life Support System (ECLSS) capabilities, ISRU systems, and the deployable thin-film arrays. Cargo units provide food and consumables storage volume, house spare parts, and carry solar panels. The initial surface habitat for the Mars One mission is depicted in Figure 5. 


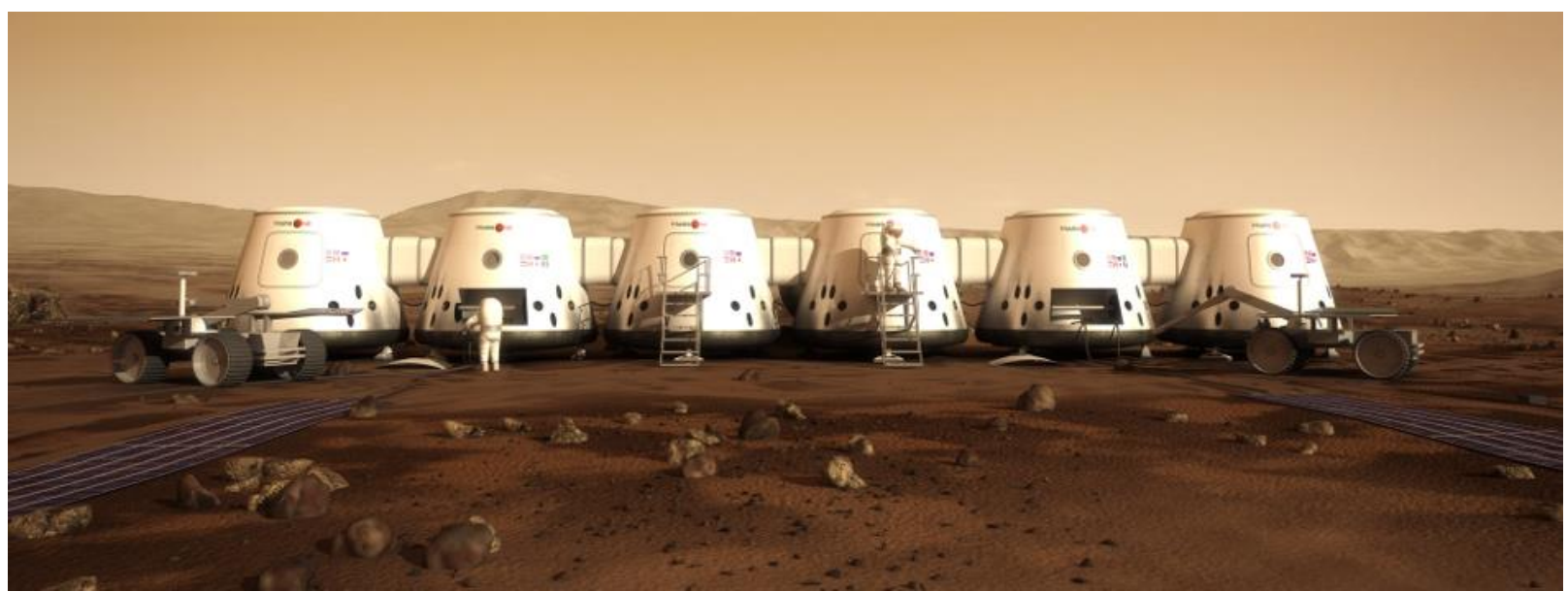

Figure 5. Mars One Surface Habitat (Courtesy Mars One Foundation) [14]

\section{F. Global Exploration Roadmap [16, 17, 18, 19]}

In 2011 and updated in 2013, the International Space Exploration Coordination Group (ISECG) published the GER. The GER "reflects ongoing dialog and continued preparation for exploration beyond low-Earth orbit beginning with the ISS and expanding human presence throughout the solar system, leading to human missions to the surface of Mars" [18]. The GER's driving principles are very similar to the EMC's strategic principles, including affordability, exploration value, international partnerships, capability evolution, human/robotic partnerships, and robustness. The ISECG GER Mission Scenario is shown in Figure 6.

Unlike the other activities described in this paper, the GER does not specifically evaluate architectural options for human exploration of Mars. Rather, the GER outlines a set of robotic and human missions to multiple beyond LEO destinations including asteroids, lunar vicinity, lunar surface, and Mars. The robotic missions to these destinations are the planned missions for all the ISECG partners. The lunar vicinity missions start with the delivery of an evolvable deep space habitat followed by several crew missions. Then, cargo is delivered to the lunar surface to prepare for the human missions. The lunar vicinity and the lunar surface missions, in conjunction with the Mars robotic missions, a Mars sample return mission, and a human-scale EDL test mission, advance capabilities needed for human Mars missions. The GER does not specifically include human missions to Mars, other than as a driving function for capability development; therefore, the GER will not be included in the Section 3 comparison. 


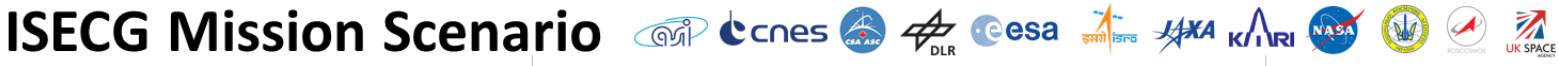

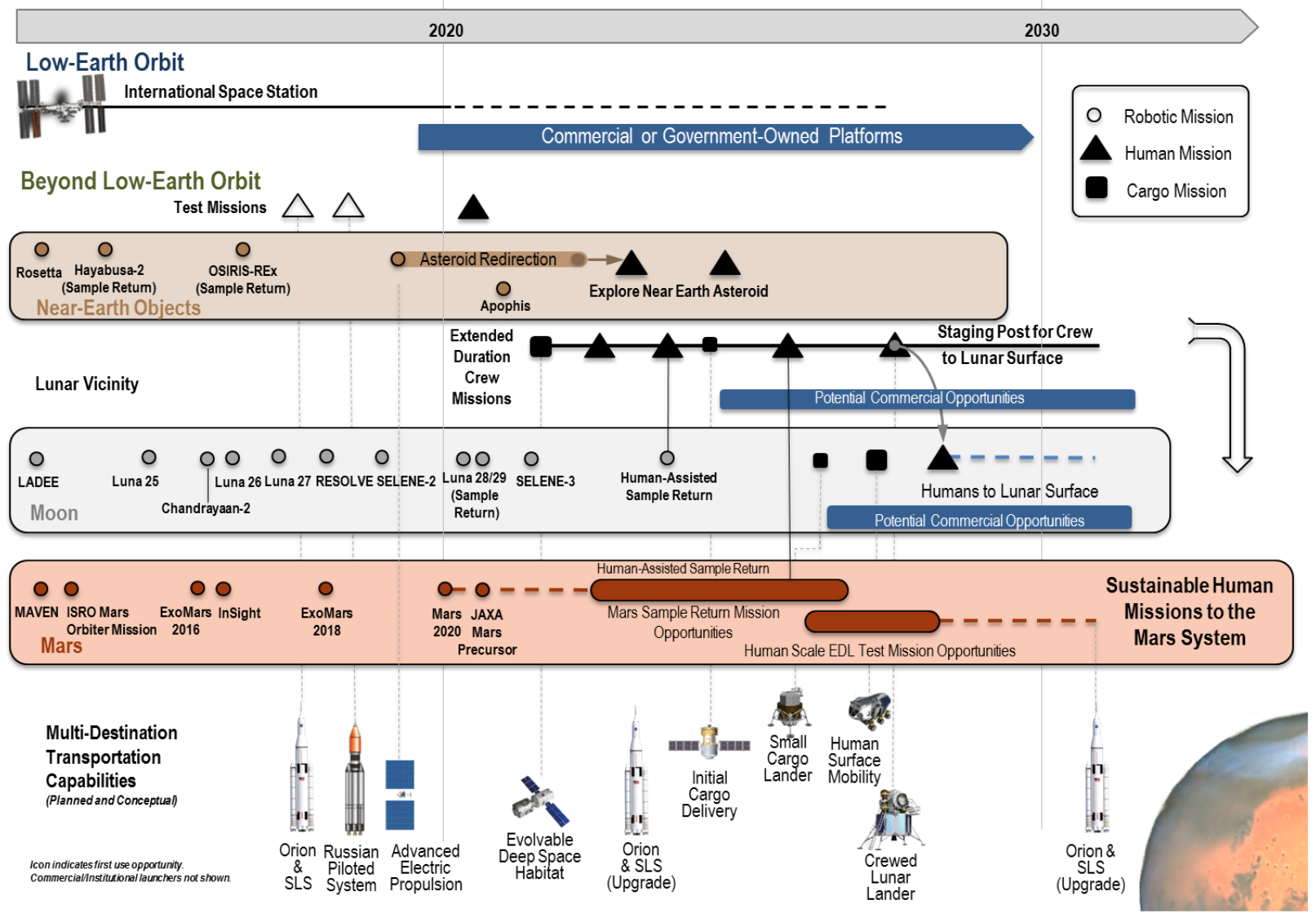

Figure 6. ISECG Mission Scenario [16]

\section{Comparison of Architectures and Campaigns}

\section{A. Metrics}

Given the diversity of the studies described in Section 2, a set of metrics was utilized to standardize comparing and contrasting the studies. Table 1 shows the evaluated metrics along with the resultant values for each of the studies. The metrics are divided into three primary categories - mission, in-space, and surface. It should be noted that the ground rules, assumptions, and analysis methods differ for each of these studies. Therefore, there may be cases where differences in metrics may not be directly attributable to differences in the approach, but rather may result from differences in the analytical method. 


\section{Table 1. Comparison of Mars Studies}

\begin{tabular}{|c|c|c|}
\hline & & Mars DRA 5.0 \\
\hline \multirow{7}{*}{.气 } & Destination & Mars Long Surface \\
\hline & Crew Size & 6 \\
\hline & Total Duration & $900-1000 d$ \\
\hline & Time in Free Space & $\begin{array}{c}400-600 d \\
(1000 \text { contingency) }\end{array}$ \\
\hline & Duration at Destination & $450-550 d$ \\
\hline & \begin{tabular}{|c|}
$\begin{array}{l}\text { No. of Critical Events for } \\
\text { Surface Missions }\end{array}$ \\
\end{tabular} & 7 \\
\hline & $\begin{array}{l}\text { Surface Capability } \\
\text { Redundancy }\end{array}$ & $\begin{array}{l}\text { Alternate Surface Capabilities } \\
\text { Initially Available }\end{array}$ \\
\hline \multirow{13}{*}{ 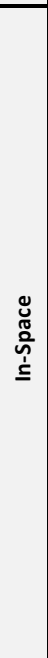 } & Orion to Mars & Yes \\
\hline & Launch Vehicles & Ares I/V ( $150-170 t$ to LEO*) \\
\hline & $\begin{array}{c}\text { Launches for 1st Surface } \\
\text { Mission }\end{array}$ & 9 over $22 \mathrm{mo}$. \\
\hline & \begin{tabular}{|l|} 
Max Launch Cadence \\
\end{tabular} & $6 / \mathrm{yr}$ \\
\hline & Min Launch Centers & $30-60 d$ \\
\hline & In-Space Propulsion & $\begin{array}{l}\text { ZBO Nuclear Cryogenic } \\
\text { Propulsion Stage }\end{array}$ \\
\hline & Crew Aggregation & LEO \\
\hline & Cargo Delivery & Split \\
\hline & Max In-Space Stage Life & 3.5 Years \\
\hline & MOI & $\begin{array}{c}\text { Propulsive (crew) } \\
\text { Aerocapture-dual use shroud } \\
\text { (cargo) }\end{array}$ \\
\hline & Return Propulsion & With Crew \\
\hline & Reuse Potential & Not Addressed \\
\hline & Earth Return & Direct $(12 \mathrm{~km} / \mathrm{s})$ \\
\hline \multirow{6}{*}{ 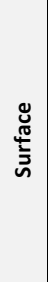 } & EDL & Entry-dual use shroud, SSRP \\
\hline & Surface Locations & Each crew to independent \\
\hline & $\begin{array}{c}\text { \# Landers / } \\
\text { Lander Capacity }\end{array}$ & $2 \times 40$ t for each crew \\
\hline & Surface Power & FSPS (40 kw total) \\
\hline & Mobility & Pres Rovers $(100+\mathrm{km})$ \\
\hline & ISRU & $\begin{array}{c}\text { Ascent Vehicle } \mathrm{O}_{2} \text { Propellant, } \\
\text { Crew } \mathrm{H}_{2} \mathrm{O} / \mathrm{O}_{2} / \mathrm{N}_{2}\end{array}$ \\
\hline
\end{tabular}

\begin{tabular}{|c|c|}
\hline EMC Split & EMC Hybrid \\
\hline Phobos/Mars Long Surface & Phobos/Mars Long Surface \\
\hline 4 & 4 \\
\hline $1000-1100 d$ & $1000-1100 d$ \\
\hline $\begin{array}{c}400-700 d \\
\text { (1100 contingency) }\end{array}$ & $\begin{array}{c}600-800 d \\
\text { (1100 contingency) }\end{array}$ \\
\hline $320-550 d$ & $300-420 d$ \\
\hline 11 & 10 \\
\hline None & None \\
\hline No & No \\
\hline SLS ( 130t to LEO*) & SLS ( 130t to LEO*) \\
\hline $\begin{array}{c}11 \text { over } 75 \text { mo. } \\
\text { (+1 for crew recovery) }\end{array}$ & $\begin{array}{c}13 \text { over } 100 \text { mo. } \\
\text { (+1 for crew recovery) }\end{array}$ \\
\hline $3 / \mathrm{yr}$ & $3 / \mathrm{yr}$ \\
\hline $120 d$ & $120 d$ \\
\hline SEP, ZBO LOX/CH4 & SEP, Hypergols \\
\hline LDRO \& LDHEO & LDRO \& LDHEO \\
\hline Split & Split \\
\hline 8 Years & $\begin{array}{c}18 \text { Years (refueled for } 3 \\
\text { missions) }\end{array}$ \\
\hline $\begin{array}{c}\text { Propulsive (crew) } \\
\text { Aerocapture-dual use HIAD } \\
\text { (cargo) }\end{array}$ & Propulsive \\
\hline Pre-positioned & With Crew \\
\hline DSH, Surface Systems & $\begin{array}{c}\text { Propulsion Elements, DSH, } \\
\text { Surface Systems }\end{array}$ \\
\hline Via LDHEO @ 11 km/s & Via LDHEO @ 11 km/s \\
\hline Entry-dual use HIAD, SSRP & Inflatable HIAD, SSRP \\
\hline Build-up at single location & Build-up at single location \\
\hline $5 \times 18 \mathrm{t}$ for 1st Crew & 5 X 18t for 1st Crew \\
\hline $3 \times 18 \mathrm{t}$ for subsequent crews & $3 \times 18 \mathrm{t}$ for subsequent crews \\
\hline FSPS (40 kw total) & FSPS (40 kw total) \\
\hline Pres Rovers $(100+\mathrm{km})$ & Pres Rovers $(100+\mathrm{km})$ \\
\hline Ascent Vehicle $\mathrm{O}_{2}$ Propellant & Ascent Vehicle $\mathrm{O}_{2}$ Propellant \\
\hline
\end{tabular}

\begin{tabular}{|c|}
\hline JPL \\
\hline $\begin{array}{c}\text { Phobos/Mars Short } \\
\text { Surface/Mars Long Surface }\end{array}$ \\
\hline 4 (2 to surface for short stay) \\
\hline $850-950 \mathrm{~d}$ \\
\hline $585-950 d$ \\
\hline 24d for short stay \\
\hline 9 \\
\hline No Pre-emplaced Capabilities \\
\hline Yes \\
\hline SLS ( 130t to LEO*) \\
\hline 6 over 54 mo. \\
\hline $3 / y r$ \\
\hline $\begin{array}{c}180 \mathrm{~d} \text { for short stay } \\
30 \mathrm{~d} \text { for long stav }\end{array}$ \\
\hline Hypergols, EUS \\
\hline HEO \\
\hline Split \\
\hline 7 Years \\
\hline $\begin{array}{l}\text { Propulsive (crew) } \\
\text { Aerocapture-dual use heat } \\
\text { shield (cargo) }\end{array}$ \\
\hline Pre-positioned \\
\hline Not Addressed \\
\hline Direct $(12 \mathrm{~km} / \mathrm{s})$ \\
\hline $\begin{array}{l}\text { Entry-dual use heat shield } \\
\text { SSRP }\end{array}$ \\
\hline Undefined \\
\hline $1 \times 23$ t for short stay \\
\hline $\begin{array}{c}3 \times 23 \text { for long stay } \\
\text { Batteries/Solar }\end{array}$ \\
\hline Unpres Rover \\
\hline None \\
\hline
\end{tabular}

\begin{tabular}{|c|}
\hline Inspiration Mars \\
\hline Mars/Venus Flyby \\
\hline 2 \\
\hline $580 d$ \\
\hline $580 d$ \\
\hline N/A \\
\hline 3 (for flyby) \\
\hline N/A \\
\hline Yes \\
\hline SLS (105t to LEO $)$ \\
\hline 1 launch (for flyby) \\
\hline $1 /$ yr \\
\hline N/A \\
\hline EUS \\
\hline N/A \\
\hline N/A \\
\hline$<2$ Years \\
\hline N/A \\
\hline N/A \\
\hline Not Addressed \\
\hline Direct \\
\hline N/A \\
\hline N/A \\
\hline N/A \\
\hline N/A \\
\hline N/A \\
\hline \\
\hline A \\
\hline
\end{tabular}

\begin{tabular}{|c|}
\hline Mars One \\
\hline Mars Long Surface \\
\hline 4 every 2 years \\
\hline Infinite \\
\hline $210-240 d$ \\
\hline Infinite \\
\hline Undefined \\
\hline $\begin{array}{c}\text { Additional Infrastructure with } \\
\text { each Crew }\end{array}$ \\
\hline $\mathrm{N} / \mathrm{A}$ \\
\hline Undefined \\
\hline Undefined \\
\hline Undefined \\
\hline Undefined \\
\hline Undefined \\
\hline LEO or HEO \\
\hline Split \\
\hline $210-240 d$ \\
\hline Undefined \\
\hline $\mathrm{N} / \mathrm{A}$ \\
\hline N/A \\
\hline N/A \\
\hline Undefined \\
\hline Build-up at a single location \\
\hline $8 \times$ ?t (first crew) \\
\hline $6 \times$ ?t (successive crew) \\
\hline Thin film solar arrays \\
\hline Undefined \\
\hline $\begin{array}{l}\text { Crew } \mathrm{H} 2 \mathrm{O} / \mathrm{O} 2 / \mathrm{N} 2 \\
\text { Food Crops }\end{array}$ \\
\hline
\end{tabular}

11

American Institute of Aeronautics and Astronautics 
There are substantial differences in both the overall philosophy and the specific architectural implementation between each of these studies. These differences will impact the performance, the programmatic sustainability, and the cost of a Mars campaign. The following sections detail key differences between studies and the major resultant impacts. As a part of each of these studies, various trades and options were evaluated. For the purposes of this comparison, the baseline mission description is referenced.

\section{PATHWAY:}

\begin{tabular}{|l|l|l|l|l|}
\hline \multicolumn{1}{|c|}{ DRA 5.0 } & \multicolumn{1}{|c|}{ EMC } & \multicolumn{1}{|c|}{ JPL } & \multicolumn{1}{|c|}{ IM } & \multicolumn{1}{c|}{ Mars One } \\
\hline -Mars Long Surface & -Phobos in 2033 & -Phobos in 2033 & -Flyby in 2021 & -Mars Long Surface in \\
in 2037 & -Mars Long Surface in & -Mars Short Surface in & & 2026 \\
-Every opportunity & 2039 & 2039 & & -Every opportunity \\
thereafter & -Every other opportunity & -Mars Long Surface in & & thereafter \\
& thereafter & 2043 & \\
\hline
\end{tabular}

Performance Impacts: The $E M C$ and $J P L$ studies assume that the path to Mars includes interim crewed missions to explore Phobos, prior to crewed missions to the Mars surface. An initial crewed mission to Mars vicinity, without descent to the surface, allows for a more progressive development of capabilities and provides for exploration of Phobos. In addition, the JPL approach also assumes an initial Mars short surface stay mission prior to the first long stay mission. Mars One and DRA 5.0 each focus on Mars surface as the initial destination. Focusing directly on the surface results in earlier human missions to Mars surface. Inspiration Mars proposes to send a crew on a flyby of Mars (and Venus) as a first step in Mars exploration. Conducting a flyby mission as an initial step significantly reduces the required capabilities to send humans to Mars space; however, the scope of exploration would be severely limited in a flyby mission.

Programmatic Sustainability Impacts: The interim Phobos mission in the $E M C$ and $J P L$ studies allows for delay in development of a Mars lander and surface capabilities, spreading out required development investments and allowing more time to develop low TRL technologies. However, visits to Phobos will require some additional unique capabilities, which will draw away the resources available for Mars surface. Conversely, Mars One and DRA 5.0 require all Mars capabilities to be developed simultaneously. This potentially results in both higher peak costs during capability development and increased developmental risk.

Risk Impacts: Impact on crew health is a significant concern for crewed Phobos and short surface stay missions. These missions require some or all of the crew to be in a micro-gravity environment for the entire mission. Since these would likely be the first crewed missions of this duration, the impacts on crew health would be largely unknown. In addition, the short mission could also potentially increase risks from radiation.

CREW DURATION:

\begin{tabular}{|c|c|c|c|c|}
\hline DRA 5.0 & EMC & JPL & IM & Mars One \\
\hline -900-1000d total & -Split: $900-1100 d$ total & $-850-950 d$ total & -580d total & -210-240d to Mars \\
-450-550d at Mars & $320-550 d$ at Mars & $-400-450 d$ at Mars & & \\
& -Hybrid: $1000-1100 d$ total & & & \\
& 300-420d at Mars & & & \\
\hline
\end{tabular}

Performance Impacts: $D R A 5.0$ relies on nuclear propulsion to minimize time in space and maximize exploration time. The total mission duration for DRA 5.0 is only 900-1000 days, of which 450-550 days are in free space and 450-550 days are spent at Mars. EMC options require up to 1100 days total duration, with up to 800 days in free space and up to 550 days at Mars. The JPL approach requires a similar total duration as EMC. However, since only a portion of the crew goes to the surface for the initial surface mission and even then only for a very short period of time, the crew is exposed to very long durations in free space. The Mars One proposal involves an entirely different paradigm than all the other missions. Because there is no return capability, all crews permanently occupy Mars.

Programmatic Sustainability Impacts: The crew duration does not directly affect programmatic sustainability for most of the mission concepts. The exception is for Mars One. Because the number of astronauts, and therefore the amount of infrastructure, progressively increases on subsequent missions, a certain amount of continuous support 
will be required to keep those crews alive, increasing programmatic burden over time to maintain the Mars surface infrastructure.

Risk Impacts: As a result of the minimal in-space duration, DRA 5.0 minimizes crew exposure to microgravity, galactic cosmic radiation (GCR), and other in-space hazards. The EMC options have similar overall durations to DRA 5.0 but somewhat longer in-space times, which will expose the crew to additional health risks. The Phobos mission in both EMC options and the Phobos and short stay missions in the JPL approach could significantly increase crew health risk because of the long durations in micro-gravity conditions. Inspiration Mars has in-space durations similar to the EMC and DRA 5.0. However, because the duration is continuous, with no interim surface stay, the crew risk could potentially be somewhat greater. The overall risk posture associated with Mars One is entirely different from all other proposed missions. With no capability to return crew members to Earth, the crews will be exposed to some degree of risk for the rest of their lives.

\section{CREW IN-SPACE PROPULSION:}

\begin{tabular}{|c|l|l|l|c|}
\hline DRA 5.0 & \multicolumn{1}{|c|}{ EMC } & \multicolumn{1}{c|}{ JPL } & IM & Mars One \\
\hline -NCPS & $\begin{array}{l}\text {-Split: } L O X / \mathrm{CH}_{4} \\
\text {-Hybrid: SEP/Storable }\end{array}$ & -Storable, EUS & -SEP, EUS & -Undefined \\
\hline
\end{tabular}

Performance Impacts: DRA 5.0 relies on a NCPS with cryogenic hydrogen $\left(\mathrm{H}_{2}\right)$ for propulsion of all elements to Mars. NCPS is a very efficient system, allowing for fast transits with minimal propellant requirements. EMC-Split and $J P L$ rely entirely on chemical propulsion to send the crew to Mars. Chemical propulsion allows for fairly rapid crew transit but is propellant intensive. EMC-Split utilize $\mathrm{LOX}-\mathrm{CH}_{4}$, which has a high efficiency but also requires ZBO capability for the propellant. JPL utilizes the EUS for crew trans-Mars injection (TMI) and a storable propellant stage for Mars orbit insertion (MOI) and trans-Earth injection (TEI). The EMC-Hybrid applies a propulsion system that utilizes both SEP and storable chemical engines for crew propulsion. The intention is to balance the high efficiency of SEP with the fast crew transit from chemical propulsion. Inspiration Mars is a free return mission, which utilizes the SLS EUS for initial Earth departure. The only required in-space propulsion is a small SEP stage used to reduce the Earth entry velocity at the end of the mission. Mars One has not defined the specific technology that will be used for in-space propulsion in published materials.

Programmatic Sustainability Impacts: NCPS is an advanced propulsion system that currently has a lower TRL than other propulsion options. It is expected that development of the system will require more time and resources and will carry additional programmatic risk. NCPS also requires the development of ZBO capability for the hydrogen propellant. In-space $\mathrm{LOX}-\mathrm{CH}_{4}$ propulsion requires the development of both new engines and $\mathrm{ZBO}$ capabilities. SEP propulsion would build off current investments being made in SEP systems, reducing development cost and risk. Storable propellant stages are reasonably mature and would require the least capability development. An additional consideration is the overlap between in-space propulsion and propulsion for the Mars descent/ascent vehicles. In cases where similar propulsion technologies can be used for the in-space stages and lander (EMC-Split, and $J P L$ ), the development efforts can be combined, reducing overall cost. Because the $J P L$ approach relies on the EUS for crew TMI, there will be required enhancements of that stage. The current design of the EUS has a very limited lifetime. The life will have to be extended to allow for the EUS to dock with other elements in high Earth orbit (HEO) and to allow sufficient time margin for launch before the Mars departure window.

Risk Impacts: Both NCPS and LOX-CH $\mathrm{CH}_{4}$ stages carry some level of increased risk because of the requirement for $\mathrm{ZBO}$ for the entire mission. Any failure to keep the propellant cooled will result in stage failure. This is particularly significant to the EMC-Split case where stages are pre-positioned and have long in-space lifetimes. Because the EUS, even with modifications, will have a limited lifetime, this will drive the margin between crew launch and Mars departure, thus potentially adding additional launch schedule risk for the JPL approach.

\section{PRE-POSITIONED CARGO/LANDERS IN-SPACE PROPULSION:}




\begin{tabular}{|c|l|l|l|l|}
\hline \multicolumn{1}{|c|}{ DRA 5.0 } & \multicolumn{1}{|c|}{ EMC } & \multicolumn{1}{|c|}{ JPL } & \multicolumn{1}{|c|}{ IM } & Mars One \\
\hline -NCPS (landers) & $\begin{array}{l}\text {-Split: SEP (landers } \\
\text { and cargo) } \\
\text {-Hybrid: SEP/Storable } \\
\text { Chem (landers and } \\
\text { cargo) }\end{array}$ & $\begin{array}{l}\text {-SEP (cargo) } \\
\text { Storable Chem/EUS } \\
\text { (landers) }\end{array}$ & & -Undefined \\
\hline
\end{tabular}

Performance Impacts: $E M C$-Split and JPL both utilize Solar Electric Propulsion (SEP) to pre-position certain cargo elements at Mars. The use of SEP to deliver cargo is advantageous because the flights utilize a high efficiency, low energy trajectory for transit to Mars. This significantly reduces propellant requirements and therefore reduces launch requirements for cargo flights. In the $J P L$ approach landers are pre-positioned via chemical propulsion, reducing the delivery time. DRA 5.0 and EMC-Hybrid each utilize their respective propulsion systems for both crew and cargo. In each case, this results in relatively fast delivery of cargo to Mars at the cost of increased total propellant requirements and much narrower departure opportunities.

Programmatic Sustainability Impacts: The cases in which different propulsion technologies are used for cargo missions (EMC-Split and JPL) necessarily require the development of multiple propulsion systems to enable the architecture.

Risk Impacts: SEP delivery of cargo exposes those missions' cargo to very long in-space durations - possibly on the order of up to 7-8 years. This could significantly increase overall mission risk, particularly when pre-positioning ZBO stages.

LAUNCH RATE AND LAUNCH CADENCE:

\begin{tabular}{|l|l|l|l|l|}
\hline \multicolumn{1}{|c|}{ DRA 5.0 } & \multicolumn{1}{|c|}{ EMC } & \multicolumn{1}{c|}{ JPL } & \multicolumn{1}{c|}{ IM } & \multicolumn{1}{c|}{ Mars One } \\
\hline $\begin{array}{l}\text {-30-60 day launch } \\
\text { centers }\end{array}$ & $\begin{array}{l}-120-180 \text { day launch } \\
\text { centers }\end{array}$ & $\begin{array}{l}\text {-180 day launch } \\
\text { centers (short stay) } \\
-30 \text { day launch } \\
\text { centers (long stay) }\end{array}$ & -Single launch & -Not specified \\
\hline-9 over 22 mo. & $\begin{array}{l}\text {-Split: } 11 \text { over } 75 \text { mo. } \\
- \text { Hybrid: } 13 \text { over } 100 \\
\text { mo. } \\
\text { (Both }+1 \text { for crew } \\
\text { recovery) }\end{array}$ & -6 over 54 mo. & -1 & -Not specified \\
\hline
\end{tabular}

Performance Impacts: DRA 5.0 and Mars One anticipate sending crews to Mars at every transit opportunity after the initial crewed mission. From an exploration and pioneering perspective, this is attractive, as it allows for continuous, or nearly continuous, crew presence on the surface. EMC and JPL send crews to Mars at every other opportunity, alternating with cargo deliveries. This extends the periods between crewed missions.

Programmatic Sustainability Impacts: Sending crews to Mars at every transit opportunity demands that both crew and cargo flights be launched to support the same opportunity. With the number of launches required, this results in high sustained launch rates. Potentially this would require additional manufacturing and launch infrastructure. However, waiting long periods between crews will reduce the pace of exploration, create gaps in public interest, and may not fully utilize capabilities. For the long surface stay mission, in which multiple landers must be sent to Mars, the JPL approach requires that two SLSs launches be conducted within approximately one month of each other. This occurs because multiple EUSs, with limited lifetimes, must be launched to support the same Mars departure window. Launching two SLSs in such a short proximity will require additional ground infrastructure.

Risk Impacts: The launch cadence and launch rate has a significant impact on mission risk. Because Mars departure dates are relatively fixed, all launches have to occur in a timely manner and the spacecraft has to be assembled for 
departure. Missions with large, sustained launch rates risk missing departure dates, delaying missions, and potentially wasting hardware.

REUSE OF IN-SPACE ELEMENTS:

\begin{tabular}{|l|l|l|l|l|}
\hline \multicolumn{1}{|c|}{ DRA 5.0 } & \multicolumn{1}{|c|}{ EMC } & JPL & IM & Mars One \\
\hline -None & $\begin{array}{l}\text {-Split: } \text { DSH } \\
\text {-Hybrid: } \text { DHS, Prop } \\
\text { Stages }\end{array}$ & -None & N/A & - None \\
\hline
\end{tabular}

Performance Impacts: Both EMC options reuse the Deep Space Habitat (DSH) by returning it to lunar vicinity at the end of the mission. The EMC-Hybrid additionally reuses the in-space propulsion stages for each mission, refueling them in lunar vicinity. The reuse of these elements reduces the need to launch new elements but requires launches to support refurbishment and refueling.

Sustainability Impacts: Reusing in-space elements reduces costs for acquiring additional hardware after the first crewed mission. However, reuse of elements also requires a program to maintain elements after each use. The DSH would have to be refurbished in lunar vicinity prior to each crewed mission, requiring additional crews to visit the DSH. The propulsion stages in EMC-Hybrid would have to be refueled in lunar vicinity. This required additional refueling infrastructure, including the development of a refueling vehicle.

Risk Impacts: Reusing the DSH significantly extends the total lifetime of the system. In DRA 5.0 and JPL, the DSH is in space for approximately three years from launch to the end of the mission. In both EMC options, if a habitat were to be reused for the Phobos mission and two subsequent surface missions, the lifetime would be up to 16 years. Although the habitat is refurbished in lunar vicinity for each mission, the overall risk of failure will increase. For EMC-Hybrid, propulsion stages will be used for multiple missions, increasing the total number of firings, and extending lifetimes up to 18 years. Because propulsion stages are not refurbished, the probability of failure will increase with lifetime. In addition, the hybrid propulsion stages must be refueled after each mission, adding complexity to the mission operations.

SURFACE STRATEGY:

\begin{tabular}{|l|l|l|l|l|}
\hline \multicolumn{1}{|c|}{ DRA 5.0 } & \multicolumn{1}{|c|}{ EMC } & \multicolumn{1}{c|}{ JPL } & IM & \multicolumn{1}{c|}{ Mars One } \\
\hline $\begin{array}{l}\text {-Independent } \\
\text { locations, no reuse }\end{array}$ & $\begin{array}{l}\text {-Single location, reuse } \\
\text { surface hab, FSPS, } \\
\text { mobility }\end{array}$ & $\begin{array}{l}\text {-Not specified, } \\
\text { potential reuse of } \\
\text { hab, power, mobility }\end{array}$ & N/A & $\begin{array}{l}\text {-Continuous } \\
\text { expansion at single } \\
\text { location }\end{array}$ \\
\hline
\end{tabular}

Performance Impacts: DRA 5.0 targets a new location of the surface for each Mars mission. A complete set of surface infrastructure is delivered to support each successive crew. Independent landing sites allow for a more distributed exploration across Mars. However, delivering a complete set of surface infrastructure for each crew increases the total number of landers and the total mass that must be delivered to Mars. EMC and Mars One return to the same site for each successive crew mission. Utilizing a single site, allows for reuse of surface hardware and a progressive build-up of surface capabilities. In addition, reusing surface infrastructure reduces the required number of landers after the first mission. For $J P L$, the initial short stay mission goes to one location and the following long stay mission to another. It is not specified if additional long stay missions would return to the emplaced infrastructure or whether additional infrastructure would be sent to a new location.

Programmatic Sustainability Impacts: Because hardware is reused for all crewed missions to the surface, in both the EMC and Mars One approaches, recurring costs for production of surface hardware, launch vehicles, and landers will be reduced.

Risk Impacts: Reuse of surface hardware extends the required lifetime for surface elements and therefore potentially increases risk. In the cases where there is redundant surface infrastructure, additional elements are available and can be used to replace failed elements, if necessary. 
MARS LANDER CAPABILITY:

\begin{tabular}{|c|l|l|l|l|}
\hline DRA 5.0 & EMC & JPL & IM & Mars One \\
\hline$-40 t$ lander & $-18 t$ lander & $-23 t$ lander & N/A & - Not specified \\
\hline
\end{tabular}

Performance Impacts: For most Mars architectures, the Mars lander capability is driven by the ascent strategy. Because the MAV is typically the largest indivisible element that must be delivered to the surface, the lander is designed to accommodate the MAV. Since the EMC relies on ISRU production of oxygen $\left(\mathrm{O}_{2}\right)$ for the MAV, the landed mass of the MAV is significantly reduced. This allows for the use of a Mars lander with a capacity of only 18t. The JPL architecture uses a fully fueled storable propellant MAV (in conjunction with a boost stage prepositioned in LMO). The fully fueled MAV necessitates a lander with a 23t capability. The DRA 5.0 lander capability is not dictated by the MAV. Rather, the landers are designed to allow all elements required for a longduration mission stay, including the crew, to be delivered on only two landers. This requires a 40t capacity lander. The impact of the MAV is most obvious on Mars One. Because Mars One includes no MAV, the mission is able to utilize a larger number of much smaller landers. Rather than delivering a large habitat for the crew, the lander cabins are joined to provide habitable space on the surface.

Programmatic Sustainability Impacts: Lander capability will have a significant impact on the required development effort. The current state of the art for Mars landers is only 1t of landed mass. The increase in lander capability from 1t to what is required for human missions will be challenging. Although the scalability of lander technology is not presently known, it is possible that progressively larger landers could potentially require more complex, lower TRL technologies to enable EDL. Ultimately, this could increase development cost and development risk.

Risk Impacts: There is a significant trade in risk between smaller and larger landers. A smaller lander capacity requires more landers to enable a mission, increasing exposure during EDL. However, it is possible that the complexity of the EDL system may be reduced, lowering the per lander risk. Conversely, a larger lander capacity requires fewer landers to enable the mission but may rely on more complex EDL systems. The initial $J P L$ surface mission requires only a single lander; this will reduce the risk associated with landing multiple landers in close proximity to each other for that mission.

CARGO PRE-POSITIONING:

\begin{tabular}{|l|l|l|l|l|}
\hline \multicolumn{1}{|c|}{ DRA 5.0 } & \multicolumn{1}{|c|}{ EMC } & \multicolumn{1}{c|}{ JPL } & IM & \multicolumn{1}{c|}{ Mars One } \\
\hline $\begin{array}{l}\text {-Crew/cargo } \\
\text { landers }\end{array}$ & $\begin{array}{l}\text {-Split: TEI/EOI stages, } \\
\text { crew/cargo landers } \\
\text {-Hybrid: Crew/cargo } \\
\text { landers }\end{array}$ & $\begin{array}{l}\text {-TEl stages, return } \\
\text { logistics, boost stage, } \\
\text { crew/cargo landers }\end{array}$ & N/A & -Landers \\
\end{tabular}

Performance Impacts: Each of the proposed approaches (except Inspiration Mars) rely on pre-positioning of some cargo, prior to the crewed mission. This reduces the overall mass of the crewed spacecraft that must be delivered to Mars vicinity. EMC, JPL, Mars One, and DRA 5.0 all pre-position landers and surface assets at Mars. The EMC and $J P L$ approaches also assume pre-positioning of Earth return stages at Mars. This further reduces the mass of the crew spacecraft and allows the stages to be pre-positioned via low-energy SEP transits. Pre-positioning of elements also allows certain options in the architectures, such as ISRU production of ascent propellant.

Programmatic Sustainability Impacts: Pre-positioning of cargo at Mars allows for additional spacing between crew and cargo launches and lowers the total required launch mass. This in turn lowers the required maximum launch cadence and reduces required launch infrastructure.

Risk Impacts: Pre-positioning of surface infrastructure and landers has the potential to increase mission risk, as the cargo is exposed to in-space and surface conditions for longer periods than if they were delivered with the crew. Conversely, pre-positioned elements can be tested on the surface prior to crew departure, reducing risk. Prepositioning of the Earth return stages also introduces additional risk. If the crew were unable to rendezvous and dock with the return stage(s), then the crew would be unable to return to Earth. 
CREW SIZE:

\begin{tabular}{|c|l|l|l|l|}
\hline \multicolumn{1}{|c|}{ DRA 5.0 } & \multicolumn{1}{|c|}{ EMC } & \multicolumn{1}{c|}{ JPL } & \multicolumn{1}{c|}{ IM } & Mars One \\
\hline -Six & -Four & $\begin{array}{l}\text {-Four (two to surface } \\
\text { for first surface } \\
\text { mission) }\end{array}$ & -Two & $\begin{array}{l}\text {-Four (additional four } \\
\text { every two years) }\end{array}$ \\
\hline
\end{tabular}

Performance Impacts: DRA 5.0 specifies a crew size of six, all of whom descend to the surface for long-stay exploration. This allows for a significant capacity to perform required maintenance and upkeep and still allows time for exploration. However, a larger crew size requires the delivery of additional logistics, increases the size of the DSH, and increases the required capability of the MAV. The EMC and Mars One studies specify a crew of four, all of who descend to the surface. The smaller crew size reduces total crew hours available for exploration but also reduces logistics requirements. In the $J P L$ concept, a crew of four travels to Mars, but only two crew descend to the surface for the short stay mission. This significantly reduces lander and MAV requirements but, along with the reduced surface duration, will limit exploration opportunities.

Programmatic Sustainability Impacts: Larger crew sizes potentially permit more opportunities for international partners, possibly allowing for international contributions.

Risk Impacts: A potential risk associated with smaller crews is time availability to maintain critical spacecraft and surface infrastructure systems. With limited abort options, the ability to maintain systems will be critical. There is potential that repair activities could overwhelm available crew time.

MARS ORBITAL INSERTION:

\begin{tabular}{|c|c|c|c|c|}
\hline DRA 5.0 & EMC & $\begin{array}{l}\text { JPL } \\
\end{array}$ & IM & Mars One \\
\hline $\begin{array}{l}\text {-NCPS (crew) } \\
\text {-Aerocapture } \\
\text { (landers) }\end{array}$ & $\begin{array}{l}\text {-Split: SEP (cargo) } \\
\text { Aerocapture (landers) } \\
\text { LOX-CH } 4 \text { (crew) } \\
\text {-Hybrid: SEP/Storable } \\
\text { Chem (cargo, landers, } \\
\text { crew) }\end{array}$ & $\begin{array}{l}\text { - SEP (cargo) } \\
\text {-Aerocapture (landers) } \\
\text {-Storable Chem (crew) }\end{array}$ & N/A & - Undefined \\
\hline
\end{tabular}

Performance Impacts: Each of the approaches (except Inspiration Mars) relies on propulsive stages for insertion into Mars orbit for the crew. This minimizes Mars sphere of influence entry forces and risk. DRA 5.0, EMC-Split, and JPL utilize aerocapture for Mars insertion for at least some cargo vehicles. To enable aerocapture, DRA 5.0 utilizes a dual-use shroud acting as both the launch vehicle fairing and the heat shield for both aerocapture and Mars entry. The EMC-Split option utilizes a dual-use HIAD on the lander for Mars insertion and entry for all landers. The use of aerocapture for MOI significantly reduces the amount of propellant required for delivery of cargo vehicles. Mars One utilizes propulsive insertion into Mars orbit for all vehicles. However, the specific propulsion technology that will be used has not been defined in published materials.

Programmatic Sustainability Impacts: Large dual-use heat shields for aerocapture are a low TRL technology and will require development and testing to enable a Mars campaign.

Risk Impacts: Aerocapture potentially introduces more risk to cargo flights, particularly for dual use systems.

\section{B. Challenges}

While differences in the ground rules, assumptions, and analysis methods can make direct comparison of these studies problematic, by evaluating the overall results, it is possible to identify outliers and trends in performance. Potential challenges were identified for each study by comparing overall metrics.

Evolvable Mars Campaign - Key challenges associated with the EMC options reflect the low assumed launch rate and the use of SEP and/or Hybrid propulsion for pre-positioning of cargo, landers, and return stages. The EMC- 
Split option relies on the use of $\mathrm{ZBO} \mathrm{LOX}-\mathrm{CH}_{4}$ stages for propulsion of the crewed vehicle. However, return propulsion stages are pre-positioned at Mars by the SEP system. Because of this, the lifetime of the $\mathrm{LOX}-\mathrm{CH}_{4}$ stages can be in space for a very long period prior to use - on the order of 7-8 years. The stages must survive and keep propellant cooled for this entire period and then reliably fire multiple times. Ensuring safety and reliability may be difficult. The EMC-Hybrid option introduces some additional challenges related to the refueling and reuse of the inspace propulsion stages. In order to reuse propulsion stages, they must be refueled in lunar vicinity. This requires the development of additional capabilities, including a refueling vehicle. The stages also must be designed with long lifetimes to allow for multiple reuses. The life of stages in this option is up to 18 years. While there is no ZBO on these stages, ensuring reliable operations over this period could be difficult.

Because the landers are pre-deployed at Mars via SEP, the landers and associated equipment have very long lifetimes on the surface. This is of particular concern for the MAV, which has a lifetime of up to 5-7 years on the surface before the crew ascends. The MAV must survive for extended durations on the surface while producing ISRU propellant. The MAV must also maintain ZBO of ascent propellant during the crewed surface duration and then reliably fire the ascent engines, all in the extreme surface environment.

The EMC-Split option is dependent on a dual-use inflatable HIAD for aerocapture into Mars orbit and Mars entry for landers. Because landers may have to loiter in Mars orbit (e.g. for rendezvous with crew), the time period between HIAD uses could be significant, possibly requiring re-inflation. This could present both technical and developmental challenges.

An additional challenge to the EMC study involved the large number of required SLS launches and the overall launch cadence. The EMC-Split option requires the launch of 12 SLS and the EMC-Hybrid 14 SLS for the initial surface mission. Because the Mars departure dates are fixed for the Hybrid and for the Split crew and, given the assumed single-string ground infrastructure (resulting in launch spacing of 120-180 days), launch delays could propagate and result in missing the Mars departure window entirely.

Both EMC concepts rely on the development and deployment of FSPS power to facilitate ISRU and exploration, placing that capability on the critical path. There could be developmental and political challenges to these types of systems.

Another challenge associated with the $E M C$ architectures involves crew health. Because the initial mission to Mars vicinity is focused on Phobos exploration, crewmembers will be exposed to micro-gravity conditions for the entire mission duration.

DRA 5.0 - The primary challenges associated with DRA 5.0 are the level of new capabilities that would need to be developed, the associated affordability of these capabilities, and the concurrent development and testing of the necessary systems. This approach involves the development of numerous new in-space and surface capabilities, including: NCPS, 40t class Mars EDL, surface fission power systems (FSPS), Mars aerocapture, long-duration habitats, a cryogenic LOX- $\mathrm{CH}_{4}$ engine for Mars descent and ascent, zero boil-off methane $\left(\mathrm{CH}_{4}\right)$ storage, and surface ISRU. Concurrent development of all of these capabilities in an affordable, sustainable manner could be very challenging.

DRA 5.0 also relies on a high launch rate to support the missions. It is anticipated that vehicles will launch on 3060 day centers to support aggregation in low Earth orbit and departure. Such a high launch rate will require additional ground infrastructure and surge manufacturing capabilities. The large number of launches in a compressed period of time could also make it difficult to successfully launch all elements in time to support the Mars departure window.

Similarly, because an entirely new set of surface infrastructure is being delivered for each crew at each Mars departure opportunity, a large number of elements will have to be produced and delivered in a short period of time.

The Mars lander specified for DRA 5.0 has a delivery capacity of 40t to the Mars surface. Although the scalability of large landers had not been fully investigated, developing such a large lander could be difficult and might involve more complex technologies and approaches than smaller landers. Also, the plan to utilize a dual-use launch vehicle shroud as a heat shield for aerocapture and Mars entry could present developmental challenges.

DRA 5.0 relies on both FSPS and NCPS. As with the EMC, there could be both developmental and political challenges with the use of nuclear systems.

DRA 5.0 utilizes direct entry at Earth return using the Orion capsule. Direct entry will require upgrades to the Orion thermal protection system to enable higher Earth entry velocities. Furthermore, the lifetime of Orion will have to be extended to allow the capsule to travel to Mars and back with the crew.

JPL Minimal Architecture - A primary challenge associated with the JPL architecture involves crew health. Because the initial mission is to Phobos and the first surface mission is a short surface stay, crew members will be 
exposed to micro-gravity (and radiation for the short surface stay) for virtually the entire mission duration. In addition, given the minimal surface architecture provided by the descent/ascent cabin, there could be challenges to how the crew lives, works, and conducts EVAs on the surface. These operations are largely undefined in the current plan.

There are additional challenges associated with the Mars lander in the JPL architecture. The large heat shield requires the development and use of a large diameter hammerhead shroud for the SLS. This shroud would be used only to support lander launches. The large, fixed heat shield would require the development of a descent engine that either swings outside of the heat shield or fires through the heat shield. Finally, the heat shield must be designed to support dual use, for both aerocapture and entry.

The JPL approach requires the use of a boost stage in LMO to allow the crew to return to the Earth return vehicle. The crew must launch from the surface, rendezvous and dock with the boost stage, and then use the boost stage to ascend to and dock with the deep space habitat. This extra rendezvous and docking in LMO potentially adds more risk to the crew for Mars ascent.

The SLS EUS is utilized to support TMI in the JPL approach. Because the EUS must rendezvous with other elements in Earth orbit prior to departure, the lifetime of the EUS would have to be extended. The lifetime of the EUS would have to be extended to a sufficient duration to allow for a high probability of successful crew launch prior to the Mars departure window. For the long surface stay mission JPL requires some launches to occur as close together as 30 days. As with DRA 5.0, such a rapid launch rate will require additional ground infrastructure and surge manufacturing capabilities. As with DRA 5.0, the Orion capsule would have to be significantly modified to support direct entry at Earth and to increase the capsule lifetime.

Inspiration Mars - Challenges to the Inspiration Mars concept primarily involve schedule and mass constraints. The 2021 departure date is fixed. The next similar flyby opportunity will not occur until approximately 2036. Although the mission only requires a limited number of new capabilities, developing these capabilities while simultaneously developing SLS and Orion could be challenging. The new capabilities necessary include: the development of a reliable long-duration deep space habitat, modification of the Orion to reduce mass and extend lifetime, and an increase in the Earth entry speed of Orion.

Because the mission is constrained to a single SLS launch, there will be challenges in meeting mass limits for the deep space habitat. Inspiration Mars anticipates that the total mass of the habitat would only be $10 t$ when fully loaded with two crew. The habitat mass must include electrical, thermal, and closed loop ECLSS systems, as well as all crew systems and any required radiation protection. In addition, the habitat mass must include all consumables, spares, and logistics required to keep the crew alive for 580 days. Fitting all of the elements in a $10 t$ habitat will be very challenging.

The 2021 free return trajectory could result in an Earth return velocity that exceeds current Orion capabilities. In this case, either an additional propulsion capability would be required to slow the spacecraft prior to Earth return or the Orion thermal protection system capabilities would have to be enhanced.

The 2021 free return trajectory requires a crewed flyby of Venus on the way to Mars. The crewed flyby introduces a number of different challenges. First, additional systems will have to be developed, including radiation protection, sunshades, and improved thermal control. Second, all of the systems must be contained within the 10t habitat allocation. Finally, there are potential crew health risks associated with radiation from such a close passage to the sun $(\sim 0.7 \mathrm{AU})$.

Mars One - The technical documentation available for the proposed Mars One mission is not as extensive as is available for the other concepts. Certain elements and operations are not described in detail. As such, it is not possible to evaluate the technical challenges associated with the approach. However, there are a number of programmatic challenges inherent in the concept. The primary challenges of the Mars One approach are related to the sustainability and self-sufficiency of a permanent settlement on Mars. For initial missions, Mars One anticipates delivering food and other consumables to Mars. For later crews, Mars One relies on the crew producing most of the consumables that they need on Mars, including food. Continuously supplying the consumables, spare parts, and maintenance items needed to keep the crew alive and critical equipment functional presents an enormous logistical challenge. As crew size increases, the amount of material that must be shipped to Mars will continue to increase. Development of functional and reliable in situ production of food and other materials, on which an increasing number of settlers would rely over time, presents numerous technical difficulties. 


\section{Lessons Learned}

While each of these concepts are very different in how they approach human travel to Mars, there are a number of features and lessons learned that are common across multiple architectures. The following sections describe some of the common lessons learned across the studies.

Split Mission Architectures: Pre-positioning of required cargo elements at Mars, prior to crew departure, significantly reduces the total required launch mass. Uncrewed flights are able to utilize slower, lower energy transits and are also able to utilize aerocapture at Mars. By segregating crew and cargo launches, the transit duration for the crewed spacecraft is minimized by sending the crew at optimal alignment between Earth and Mars. Cargo can then be delivered utilizing slower, lower energy trajectories. In addition, pre-positioning of cargo spaces out the launch schedule and increases overall mission flexibility. Pre-positioning of surface infrastructure enables ISRU production of the ascent propellant, allowing time for the propellant to be produced before the crew descends to the surface. Pre-positioning of destination elements also allows for those elements to be fully tested in place before crew departure.

Conjunction Missions: All of the options that send crew to Mars orbit and return them to Earth $(E M C, J P L$, and DRA 5.0) utilize a "conjunction class" approach to the return trajectory. In this class of mission, minimal energy trajectories are utilized for both the outbound and Earth return crew transits. The crew must remain at Mars for periods of approximately 300-550 days, awaiting the proper planetary alignment for return. Conjunction class missions minimize the total energy and propellant required for the crew portion of the mission and allows for long durations for exploration at Mars.

On the other hand, JPL evaluated an option for a mission where the crew only spends 30-40 days at Mars. This option reduces the total mission duration to only about 570 days and would not require the crew to remain in Mars orbit following a short surface stay. However, this option requires that two, rather than one, TEI stages be prepositioned at Mars and requires a Venus flyby during the return. Each TEI stage would also be somewhat larger than the single TEI stage in the conjunction mission, requiring longer SEP delivery times [8].

Mars Surface ISRU: The mass of the largest single surface element that must be delivered to Mars typically drives the required capacity of the Mars lander and therefore the entire transportation system. Typically, the largest element is the MAV. Producing propellant and/or oxidizer locally at Mars allows for a significant reduction in the total mass of the MAV. Producing other consumables such as oxygen, water, or food at Mars also reduces total landed mass, potentially reducing the number of required landers.

Mars Surface Power: Power becomes a critical resource for enabling exploration at Mars. High capability power systems (FSPS or solar) provide increased ability to support astronauts on the surface, to explore Mars via mobility, to conduct scientific investigations, and to improve surface infrastructure. High capability power systems also enable surface ISRU. In addition, FSPS is resilient to Mars dust storms, is latitude independent, and provides continuous power even during eclipse periods.

Aerocapture of Cargo at Mars: Utilizing aerocapture at Mars for cargo elements and/or landers significantly reduces overall propellant requirements. Aerocapture eliminates the need to launch and send an MOI stage to Mars, which reduces overall launch requirements. In addition, use of aerocapture could potentially allow for a one-launch, direct to Mars option for certain cargo flights, which would eliminate the need for assembly in Earth space.

Pre-Cursor Activities: Near-term activities, including detailed surveys of conditions on Mars, and testing of exploration capabilities are key to enabling human exploration of Mars. Each of these studies demonstrates that they will require capability testing and knowledge gaps that can only be addressed at Mars. A step-wise exploration campaign, where capabilities are tested and evaluated over time, building to a human Mars mission, provides for a greater probability of success.

Sustained Mission Cadence: A sustainable Mars exploration campaign will include a recurring series of ever more challenging achievements and involve repeated crew missions to the surface. In order to justify the costs of developing a human Mars architecture, the system must demonstrate value over time. This includes both near-term and long-term exploration and sustained exploration on the planetary surface. 


\section{Conclusions}

There are several approaches currently being studied or recently studied that explore sending humans to Mars vicinity or Mars surface. The concepts outlined in this paper vary from a single flyby mission to permanent settlement of Mars. While the philosophy and goals of individual studies may vary, many of the challenges that must be overcome are similar. By comparing and contrasting different concepts, it is possible to identify promising solutions to these challenges. Ultimately, a successful Mars campaign will integrate ideas and concepts across mission studies, applying the lessons that are learned in developing each of these approaches.

\section{Acknowledgments}

The authors would like to thank Bret Drake (NASA Johnson Space Center) and Pat Troutman (NASA Langley Research Center) for a thorough review of the paper and their insights on the Evolvable Mars Campaign and Mars Design Reference Mission 5.0.

\section{References}

[1] Craig, D., Herrmann, N., and Troutman, P., "The Evolvable Mars Campaign - Study Status," 2015 IEEE Aerospace Conference, Big Sky, MT, 2015.

[2] Craig, D., Herrmann, N., and Troutman, P., "Pioneering Space Through the Evolvable Mars Campaign," 2015 AIAA Space Conference, Pasadena, CA, 2015.

[3] Percy, T., McGuire, M., and Polsgrove, T., "In-space Transportation for NASA's Evolvable Mars Campaign," 2015 AIAA Space Conference, Pasadena, CA, 2015.

[4] Merrill, R., Chai, P., Jones, C., Komar, D., and Qu, M., “An Integrated Hybrid Transportation Architecture for Human Mars Expeditions,” 2015 AIAA Space Conference, Pasadena, CA, 2015.

[5] Drake, B., Human Exploration of Mars Design Reference Architecture 5.0. NASASP-2009-566. Washington, D.C.: National Aeronautics and Space Administration, 2009.

[6] Drake, B., Human Exploration of Mars Design Reference Architecture 5.0 Addendum. NASASP-2009-566-ADD. Washington, D.C.: National Aeronautics and Space Administration, 2009.

[7] Drake, B. and Watts, K., Human Exploration of Mars Design Reference Architecture 5.0 Addendum \#2. NASASP-2009566-ADD2. Washington, D.C.: National Aeronautics and Space Administration, 2014.

[8] Price, H., Baker, J., and Naderi, F., “A Minimal Architecture for Human Journeys to Mars,” New Space [online journal], Vol. 3, No. 2, Online ISSN: 2168-0264, URL: http://www.liebertpub.com/space, 2015.

[9] Holladay, J.B., et al., “Ares V Utilization in Support of a Human Mission to Mars”, NASA/TM-2010-2164450.

[10] Price, H., Baker, J., Strange, N., and Woolley, R., "Human Mission to Mars Orbit, Phobos, and Mars Surface Using 100kWe-Class Solar Electric Propulsion", American Institute of Aeronautics and Astronautics, AIAA 2014-4436, 2014.

[11] http://www.inspirationmars.org/

[12] “Architecture Study Report Summary" Inspiration Mars Foundation, Document Number: 806800151NC

[13] "Mars Flyby 2021: The First Deep Space Mission for the Orion and Space Launch System", Hearing of the House Committee on Science, Space, and Technology, House, $113^{\text {th }}$ Congress (Testimony of Douglas R. Cooke).

[14] http://www.mars-one.com/mission

[15] "Mars One Habitat ECLSS (ECLSS) Conceptual Design Assessment", Paragon Space Development Corporation, Document Number: 807300009, Rev. B., 2015.

[16] “The Global Exploration Roadmap,” International Space Exploration Coordination Group, Washington, D.C., 2013.

[17] “The Global Exploration Roadmap,” International Space Exploration Coordination Group, Washington, D.C., 2011. 
[18] Hufenbach, B., Laurini, K., Satoh, N., Lange, C., Martinez, R., Hill, J., and Spiero, F., "The Exploration Mission Themes of the Global Exploration Roadmap," 65 ${ }^{\text {th }}$ International Astronautical Congress 2014, IAC-14,B3,1,10,x22313, Toronto, Canada, 2014.

[19] https://www.nasa.gov/exploration/about/isecg/\#.VZnWB lViko 